\title{
Feasibility of Classifying Life Stages and Searching for the Determinants: Results from the Medical Expenditure Panel Survey 1996-2011
}

\author{
Yi-Sheng $\mathrm{CHAO}^{1 *}$, Hau-tieng $\mathrm{Wu}^{2,3}$ and Chao-Jung $\mathrm{Wu}^{4}$ \\ ${ }^{1}$ Centre de recherche du centre hospitalier de l'Université de Montréal (CRCHUM), Université de Montréal, Montréal, QC, \\ Canada, ${ }^{2}$ Department of Mathematics, University of Toronto, Toronto, ON, Canada, ${ }^{3}$ Mathematics Division, National Center \\ for Theoretical Sciences, Taipei, Taiwan, ${ }^{4}$ Département d'Informatique, UQAM, Montréal, QC, Canada
}

\section{OPEN ACCESS}

Edited by:

Richard Eugene Frye,

Arkansas Children's Hospital Research Institute, United States

Reviewed by:

Piotr Romaniuk,

Medical University of Silesia,

Poland

Albert Okunade,

University of Memphis,

United States

*Correspondence:

Yi-Sheng CHAO

chaoyisheng@post.harvard.edu

Specialty section:

This article was submitted to Child Health and Human Development,

a section of the journal

Frontiers in Public Health

Received: 09 June 2017 Accepted: 31 August 2017

Published: 27 October 2017

Citation:

CHAO Y-S, WU H-t and WU C-J (2017) Feasibility of Classifying Life

Stages and Searching for the

Determinants: Results from the Medical Expenditure Panel Survey

1996-2011.

Front. Public Health 5:247. doi: 10.3389/fpubh.2017.00247
Background: Life stages are not clearly defined and significant determinants for the identification of stages are not discussed. This study aims to test a data-driven approach to define stages and to identify the major determinants.

Methods: This study analyzed the data on the Medical Expenditure Panel Survey interviewees from 1996 to 2011 in the United States. This study first selected features with the Spearman's correlation to remove redundant variables and to increase computational feasibility. The retained 430 variables were log transformed, if applicable. Sixty-four nominal variables were replaced with 164 binominal variables. This led to 525 variables that were available for principal component analysis (PCA). Life stages were proposed to be periods of ages with significantly different values of principal components (PCs).

Results: After retaining subjects followed throughout the panels, 244,089 were eligible for PCA, and the number of civilians was estimated to be 4.6 billion. The age ranged from 0 to 90 years old $($ mean $=35.88,95 \% \mathrm{Cl}=35.67-36.09$ ). The values of the first PC were not significant from age of 6 to 13, 30 to 41, 46 to 60, and 76 to 90 years (adjusted $p>0.5$ ), and the major determinants were related to functional status, employment, and poverty.

Conclusion: Important stages and their major determinants, including the status of functionality and cognition, income, and marital status, can be identified. Identifying stages of stability or transition will be important for research that relies on a research population with similar characteristics to draw samples for observation or intervention.

Contribution: This study sets an example of defining stages of transition and stability across ages with social and health data. Among all available variables, cognitive limitations, income, and poverty are important determinants of these stages.

\footnotetext{
Keywords: life stages, principal components, principal component analysis, medical expenditure panel survey,
} stages of transition, stable stages

Abbreviations: MEPS, Medical Expenditure Panel Survey; PCA, principal component analysis; ADL, activities of daily living; IADL, instrumental activities of daily living; PHQ-2, Patient Health Questionnaire; PC, principal component; PC1, the principal component explaining the most portion of total variance; PC2, the principal component explaining the second most portion of total variance. 


\section{INTRODUCTION}

Life course perspective links exposures in early life to incidence in later life and has been proven useful to understand distant courses of particular events, such as cardiovascular diseases and diabetes $(1,2)$. For example, life course epidemiology attempts to find the associations between childhood trajectories and the outcomes in later life $(2,3)$. Although similar ideas have been widely applied and embedded in terms like adolescence (4) and adulthood (1), it is still unclear how stages that consist of a life course could be clearly defined (1). There are theories on the transitions or trajectories of life (5), some of which are supported by evidence, to show that physiological functions evolve with different developmental stages $(6,7)$ and health trajectories differ at the end of life (8-10). However, these definitions might not be suitable for general questions, such as what is the beginning of aging (11) and what characteristics can be used to define healthy aging and trajectories? These questions are usually complicated by socioeconomical activities. Therefore, a population perspective is inevitable, and explicit criteria to extract information from population data should be established, if we would like to study the diverse nature of life course.

To address the need to have a better understanding of life course from a population perspective and to establish criteria for data extraction, we consider the Medical Expenditure Panel Survey (MEPS) database that documents several distinctive dimensions of life course, especially socioeconomic status, functionality, and health status. The MEPS is a source of information with important characteristics, especially national representativeness and age coverage from 0 to 90 years (12). The main theme of the MEPS includes health insurance coverage, health-care consumption, and incurred expenditures (12). It also contains a wide range of individual information on demographics, income and tax filing, health status, disability, access to care, employment, health insurance and health utilization with information on expenditure and source of payment (12). For health status, detailed information is collected on activities of daily living, instrumental activities of daily living, vision, hearing, changes in limitations, child health and preventive care, and other dimensions measured by SF-12, smoking status, Kessler Index (K6), Patient Health Questionnaire, and attitudes about health (12). Due to its rich set of variables on individual status, national coverage, and longitudinal components, the MEPS data are not only used in the health expenditure estimation but also in other social research topics, such as income tax simulations $(13,14)$, employment, social determinants of health (15), and longitudinal research on individual or family behaviors (12). The inclusion and balance of social and health dimensions in the MEPS database is one of the best resources available for us to establish explicit criteria to understand population data from a life course perspective.

This study aims to test the feasibility of a data-driven approach to classify potential life stages and search for determinants of the components with data on health and health-care utilization. First, we attempt to identify representative components of the population data based on applying a commonly used data summary method, linear or ordinary principal component analysis (PCA). Second, we search for life stages within the principal components
(PCs) of the database. Finally, we interpret the identified life stages with the variables that are highly associated with them.

\section{DATA AND METHODS}

The data were explored by PCA and represented by PCs. In this work, the PCs were taken as representative components or leading trajectories in a life course perspective in this exploratory project. The leading PCs might represent distinctive dimensions of life course, since they were found to be composed of distinctive input variables. A life stage is defined to be a period of consecutive ages, during which the chosen leading trajectories has a small variation. The chronological ages between life stages were stages of transition. The entire analytical process is shown step by step below.

\section{Data Sets}

This study analyzed the 16 longitudinal panels released from the MEPS that were conducted annually among the civilian noninstitutionalized population to produce nationally representative statistics since 1996 in the United States (16). Each panel lasted for 2 years and consisted of five rounds of data collection (17).

\section{Data Linkage and Processing}

The 16 longitudinal panels of the MEPS were pooled and merged by variable names common to all panels. There were $1,989 \mathrm{com}$ mon variables across 16 panels (for panels beginning throughout 1996 and 2011, see Datasheet 1 in Supplementary Material for the list of variables and their characteristics). Only subjects participating throughout the 2-year panels were retained in the data set, in addition to those deceased after a 1-year follow-up and before the end of the 2-year panels. Administrative variables and the variables that were used to flag certain circumstances in the process of data gathering were not used for analysis. The result was that only the 789 variables containing individual information in the first years of the 2-year panels were eligible for analysis.

Reserved values that identified specific responses across all variables were recoded according to the MEPS codebooks: -2 recoded to the same answers in previous rounds, -1 to inapplicability and others to missing values $(-3,-7,-8$, and -9 for "no data in round," "refused," "do not know," and "not ascertained," respectively; see Datasheet 1 in Supplementary Material for the proportions of these categories in the variable list). The proportions of missingness ranged from 0 to $23.62 \%$ (median $0.01 \%$ among 644 variables with any missing values, see Datasheet 1 in Supplementary Material for the proportions of missingness). Missing values in all variables were imputed with the multivariate imputation by chained equations (18). The skewness of each continuous variable was evaluated from the raw data, without adjusting the survey design. Log transformation was applied, if the skewness of a log-transformed variable was less than that of the original variable (19).

\section{Feature Selection with Spearman's Rank-Order Correlation}

This study first selected features with a correlation-based method proposed for the purpose of removing redundant variables and 
increasing computational feasibility $(20,21)$. The data redundancy might be created for the ease of survey implementation or data labeling. For example, different sources of income were asked about separately, and total income was the sum of incomes from all sources (22). The levels of education might be presented as years spent in school or types of highest grades completed (22) (see Datasheet 1 in Supplementary Material for details on variable names and labels).

First, sex and race/ethnicity were excluded, since they do not provide dynamical information. Age is also excluded, so that we could examine the life stage without the influence of the physical status. Spearman's rank-order correlation was used to create a correlation matrix of all variables, categorical, or continuous (20, 21). The threshold for redundancy was Spearman's rank correlation coefficient greater than 0.9 (23). There were 430 variables left for further analysis (see Figure $\mathbf{1}$ for the flowchart).

Of the 71 categorical variables, 12 ordinal variables that ranked poverty categories, difficulty in using fingers to grasp, self-rated health status, and self-rated mental health status and a summary measure of vision impairment were not transformed to dummy variables. Another 59 nominal variables were replaced with 154 multiple binominal variables. This results in 525 variables that were available for PCA. There were an additional 15 variables

\begin{tabular}{|c|}
\hline $\begin{array}{c}\text { MEPS panel data sources: } \\
16 \text { panels from } 1996 \text { to } 2012 \\
\text { (http://meps.ahrq.gov/mepsweb/data_stats/download_data_files.jpp) }\end{array}$ \\
\hline$\downarrow$ \\
\hline $\begin{array}{l}\text { Combining MEPS panels: } \\
\text { 1. Common variables: } 1988 \\
\text { 2. Identification of variable characteristics } \\
\text { 3. } 244,089 \text { observations participating in two-year panels and those } \\
\text { deceased before the end of panels, out of } 248,033 \text { in total }\end{array}$ \\
\hline 1 \\
\hline $\begin{array}{l}\text { Data cleaning based on the reserved values }(-3,-7 \text { to }-9) \text { and log- } \\
\text { transformation for skewed continuous variables if appropriate }\end{array}$ \\
\hline 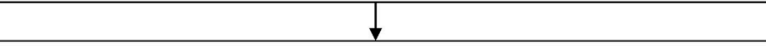 \\
\hline $\begin{array}{l}\text { Missing value imputation: } \\
\text { Proportions of missingness ranging from } 0.05 \% \text { to } 7.60 \% \text { in } 83 \text { variables }\end{array}$ \\
\hline$\downarrow$ \\
\hline $\begin{array}{l}\text { Feature selection with Spearman's rank-order correlation: } \\
430 \text { variables retained ( } 71 \text { categorical and } 359 \text { continuous) and } 154 \\
\text { binary variables created to replace } 59 \text { nominal variables }\end{array}$ \\
\hline$\downarrow$ \\
\hline $\begin{array}{l}\text { Principal component analysis (PCA) } \\
\text { 1. Proportions of variance explained by } 525 \text { PCs } \\
\text { 2. Variances contributed by variables in each PC }\end{array}$ \\
\hline$\downarrow$ \\
\hline $\begin{array}{l}\text { Trends of PCs by age } \\
\text { 1. Mean values of first } 16 \text { PCs } \\
\text { 2. Pairwise comparisons of first two PCs by ages } \\
\text { 3. Interpretation of PCs by approximating PCs with input variables }\end{array}$ \\
\hline
\end{tabular}

FIGURE 1 | Flowchart of data linkage, data processing, and feature selection with the Medical Expenditure Panel Survey (MEPS) 1996-2011. that were used for personal identification and control for survey design.

\section{Principal Component Analysis}

Principal component analysis was proven to be useful for dimension reduction or data preprocessing (24). We considered linear or ordinary PCA as the optimal and most feasible option in consideration of complex survey design (25). Although there are different variations of PCA $(24,26,27)$ or similar data techniques $(28,29)$, there were limited choices of dimension reduction methods under the complex survey design (30). Before PCA, each variable was centered to 0 and scaled to unit variance. The PC comes from projecting input variables to the determined principal vector. The leading PCs had the largest variances and explained the largest proportions of total variances in a database. In this study, PCA was conducted with the 525 variables, while adjusting for complex survey design (30).

The contributions of variable variance to each PC were calculated in two steps. First, for each PC, the associated squared loadings of all input variables were obtained. These squared loadings ranged from 0 to 1 . The contribution of the ith input variable in each PC is then defined as the variance of each PC was multiplied by the $i$ th squared values.

\section{Proposed Life Stages}

The proposed life stage is evaluated from the first or second PC. We partition the dataset into subsets according to age, ranging from 0 to 90 years old. The age is determined on December 31 of each year. Each age subset consists of subjects with the same age, and there are a total of 91 age subsets. We view the $p$ value $<0.05$ as statistical significant, and the $p$ values were adjusted for multiple comparisons with the Benjamini-Hochberg method (31). We call a group of consecutive age subsets stable, if less than $5 \%$ of all pairs of age subsets are different with statistical significance. In practice, the life stages were searched in the following greedy manner. We began with the age 0 subset and tested whether the $\mathrm{PC}$ value at that age subset was significantly different from the age one subset. If there was no significant difference, we found a stable group consisting of age 0 and 1 subset. We continued the iteration, and supposed that we find a stable group consisting of age 0 to age $i$ subsets, where $i>1$. We then determined if the group that consisted of age 0 to age $i+1$ subsets is a stable group. This search stops when the age $j$, where $j>i$, does not belong to the stable group consisting of age 0 to age $j-1$ subsets. We then restart the greedy iteration from the age $j$ subset and view the stable group consisting of age 0 to age $j-1$ subsets as an isolated group. This greedy algorithm ends when the 91 age subsets are exhausted. We call the period of consecutive ages in a stable group longer than 5 years a life stage. The ages between any two life stages were considered stages of transition.

\section{PC Approximation and Interpretation}

For the purpose of interpretation, the PCs were approximated with input variables using a linear regression model. The approximation method assessed the relative importance of all input variables in terms of $R^{2}$ regarding each PC. We applied the forward selection to include input variables in the linear 
regression model. There were no limits on the number of input variables that could be used to approximate each PC. The PCs were interpreted according to the regression coefficients of the input variables.

This study adopted R (v. 3.20 released in April 2015) and R Studio (v. 0.99.441 released in May 2015) for data analysis. The complex survey design of the MEPS was accounted for with the survey package (30), except for Spearman's rank-order correlation and multiple imputations that required more computational capacity than what we could afford. The $R^{2}$ used to select the input variables for PC interpretation was assessed with the relaimpo package (32).

\section{RESULTS}

\section{Population Characteristics}

There were 248,033 subjects available in panels $1-16$ of the MEPS between 1996 and 2011 in the United States. After retaining those participating throughout 2-year panels and those deceased during the panels, a total of 244,089 were used for PCA. Adjusting for survey design, the populations and the demographic characteristics were tabulated for the survey years in Table 1. With a weighting, the numbers of civilians were estimated to be 270 million in 1996 to 312 million in 2011, totaling 4.6 billion. The proportion of females $(51.06 \%$ of the total) did not change significantly $(p=1)$. The mean ages increased from 34.69 to $37.20(p<0.001)$, while the proportion of whites (from 81.70 to $79.89 \%, p=0.21$ ) did not change significantly in the study period. The population by gender and age were plotted with the variances of the 525 PCs in Figure 2. Despite the decline of population numbers with the advanced age, the sum of variances of all PCs continued to increase after 45 years of age. In Figure 3, the proportions of explained variance by the first 20 PCs were shown. Most PCs did not explain more than $1 \%$ of total variances. The proportions explained by the first five PCs were as following: 48.24, 3.28, 2.72, 1.41 , and $1.26 \%$, respectively.

\section{Variables Contributing to the Variability of First PCs}

In Tables 2-4, the variables were sorted by the contributed variance of the 40 leading variables for PC1 (first PC), PC2 (second PC), and PC3 (third PC). The leading variable, in terms of the variance contributed to PC1, was the amount spent on home health non-agency workers (hhnwcpy1, 99.3\% variance contributed), followed by other measures on healthcare utilization (dvowcpyl, zidosryl, and many others) that included home care, dental care, emergency room use, prescriptions, and clinical visits (Table 2). There were 125 variables whose contributions to PC1 are $>0.9$ and 177 variables whose contributions are $>0.8$.

The leading variables, in terms of the contributed variances to PC2, were public insurance coverage (pubjaylx.1, pubdey1x.1, and inscovy1.2), employment-related variables (empst1.4), and functional limitations (actlim1.1, wlklim1.1, anylimy1.1, Table 3). However, there were only three variables contributing more than
0.5 to PC2. In Table 4, there were no variables contributing more than $50 \%$ of their own variances to PC3. The leading variables for PC3 were related to the amount of health-care expenditures paid by private insurance and coverage of employment-related insurance. For the other PCs, the contribution of the leading variable decreased.

\section{Life Stages}

The mean values of the first 16 PCs were plotted in Figures 4 and 5. The first eight PCs had changes of greater magnitude than the 9-16th PCs between age of 0 and 90 years. To test the significance of the changes in PC values, Figures 6 and 7 present the pairwise comparisons of the PC1 and PC2 by age, respectively. By setting the insignificant values to blank in the matrix of differences, there were clusters of blank cells along with the diagonal axis that labeled years of age. In the gray rectangles, the covered areas had less than $5 \%$ of significant differences of all cells in the areas. Therefore, the age ranges covered by gray rectangles were stages with populations of similar PC values. The values of PC1 were not different from 6 to 13,30 to 41,46 to 60 , and 71 to 90 (adjusted $p$ values $>0.05$ for more than $95 \%$ of all pairwise comparisons). The values of PC2 were not different from 12 to 18,29 to 38 , and 41 to 45 years.

\section{Major Determinants of PCs}

To have a good approximation of PC1 and PC2 $\left(R^{2}>0.8\right)$, it required 13 and 41 variables (see Table 5 for a partial list). The leading variables that explained the most of the $\mathrm{PC} 1$ variance were income and poverty status, functional and cognitive limitations, marital status, and perceived health status. In addition to marital status, cognitive limitations and income, social security income, clinical visits and healthcare expenditures covered by Medicare, and employment status were the leading variables explaining PC2. The life stages identified with the first two PCs, especially $\mathrm{PC} 1$, were associated with the statuses of marital status, income and cognitive limitations.

\section{DISCUSSION}

\section{Research Implications}

This study showed that a complex dataset like the MEPS could be summarized and life stages could be adaptively identified from the data, based on the explicit criteria and statistical tests. There are several research implications. First, this is the first attempt to systematically assess the data from all age groups to better define and identify stages of stability or transition. This method can be applied to other data sets to construct a systematic process and to obtain an insight from the stages of stability and transition.

Second, the identification of life stages is important for research that relies on a research population with similar characteristics to draw samples for follow-up or intervention $(33,34)$. The gray rectangles in Figures $\mathbf{6}$ and $\mathbf{7}$ show that: civilians from the same stable life stages could be more comparable than those in transition stages, in terms of the PC values. Third, these life stages are also important for epidemiological investigation that sometimes a population stratification is needed to augment sample sizes in 
TABLE 1 | Demographic characteristics of the populations in the Medical Expenditure Panel Surveys from 1996 to 2011.

\begin{tabular}{|c|c|c|c|c|c|c|c|c|c|c|}
\hline Year & $\begin{array}{l}\text { Unweighted } \\
\text { sample sizes }\end{array}$ & $\begin{array}{c}\text { Weighted } \\
\text { sample sizes }\end{array}$ & $(95 \% \mathrm{Cl})$ & Mean Age & $(95 \% \mathrm{Cl})$ & Female & $(95 \% \mathrm{Cl})$ & & & \\
\hline 1996 & 19,526 & $270,220,553$ & $(252,162,541-288,278,566)$ & 34.56 & $(33.98-35.14)$ & $51.14 \%$ & $(50.44-51.84 \%)$ & & & \\
\hline 1997 & 12,242 & $272,924,582$ & $(243,656,703-302,192,462)$ & 34.65 & $(33.91-35.39)$ & $51.12 \%$ & (50.29-51.94\%) & & & \\
\hline 1998 & 9,956 & $275,276,754$ & $(240,859,963-309,693,544)$ & 34.98 & $(34.23-35.72)$ & $51.38 \%$ & (50.42-52.34\%) & & & \\
\hline 1999 & 13,120 & $277,777,364$ & $(228,792,966-326,761,762)$ & 34.90 & $(34.20-35.59)$ & $51.27 \%$ & (50.52-52.02\%) & & & \\
\hline 2000 & 10,237 & $282,678,581$ & $(234,159,408-331,197,754)$ & 35.36 & $(34.62-36.10)$ & $51.21 \%$ & (50.22-52.19\%) & & & \\
\hline 2001 & 20,823 & $287,502,824$ & $(256,045,871-318,959,777)$ & 35.54 & $(34.97-36.11)$ & $51.17 \%$ & $(50.57-51.78 \%)$ & & & \\
\hline 2002 & 15,911 & $289,917,944$ & $(259,399,447-320,436,441)$ & 35.62 & $(35.07-36.17)$ & $51.02 \%$ & $(50.26-51.78 \%)$ & & & \\
\hline 2003 & 15,972 & $292,395,934$ & $(260,225,236-324,566,631)$ & 35.80 & $(35.21-36.39)$ & $50.99 \%$ & (50.36-51.62\%) & & & \\
\hline 2004 & 15,839 & $295,173,059$ & $(268,065,034-322,281,084)$ & 36.02 & $(35.37-36.68)$ & $51.07 \%$ & $(50.31-51.83 \%)$ & & & \\
\hline 2005 & 15,388 & $298,082,232$ & $(270,107,505-326,056,960)$ & 36.07 & $(35.49-36.66)$ & $50.91 \%$ & (50.14-51.68\%) & & & \\
\hline 2006 & 16,260 & $299,880,574$ & $(277,192,459-322,568,689)$ & 36.20 & $(35.60-36.80)$ & $50.93 \%$ & $(50.27-51.59 \%)$ & & & \\
\hline 2007 & 12,237 & $302,814,992$ & $(282,485,055-323,144,928)$ & 36.62 & $(35.84-37.39)$ & $51.03 \%$ & $(50.26-51.79 \%)$ & & & \\
\hline 2008 & 17,995 & $305,990,159$ & $(289,452,089-322,528,230)$ & 36.39 & $(35.71-37.08)$ & $50.79 \%$ & $(50.05-51.53 \%)$ & & & \\
\hline 2009 & 15,993 & $307,472,984$ & $(289,097,025-325,848,943)$ & 36.61 & $(35.99-37.22)$ & $50.85 \%$ & $(50.16-51.54 \%)$ & & & \\
\hline 2010 & 14,338 & $310,617,388$ & $(293,660,354-327,574,423)$ & 37.02 & $(36.40-37.65)$ & $51.17 \%$ & $(50.36-51.97 \%)$ & & & \\
\hline 2011 & 18,252 & $312,413,749$ & $(294,383,582-330,443,916)$ & 37.19 & $(36.45-37.92)$ & $51.09 \%$ & $(50.40-51.78 \%)$ & & & \\
\hline All & 244,089 & $4,681,139,673$ & $(4,502,416,344-4,859,863,002)$ & 35.88 & $(35.67-36.09)$ & $51.07 \%$ & $(50.87-51.27 \%)$ & & & \\
\hline Year & White & (95\% Cl) & Black & $(95 \% \mathrm{Cl})$ & $\begin{array}{l}\text { American Indians/ } \\
\text { Alaska natives }\end{array}$ & $(95 \% \mathrm{Cl})$ & $\begin{array}{l}\text { Native Hawaiian/ } \\
\text { Pacific islanders }\end{array}$ & $(95 \% \mathrm{Cl})$ & $\begin{array}{c}\text { Multiple } \\
\text { races }\end{array}$ & $(95 \% \mathrm{Cl})$ \\
\hline 1996 & $81.64 \%$ & $(79.97-83.31 \%)$ & $13.18 \%$ & $(11.73-14.64 \%)$ & $1.30 \%$ & $(0.87-1.74 \%)$ & $3.79 \%$ & $(3.03-4.56 \%)$ & & \\
\hline 1997 & $82.68 \%$ & (80.61-84.75\%) & $13.08 \%$ & (11.11-15.05\%) & $0.93 \%$ & $(0.62-1.24 \%)$ & $3.31 \%$ & $(2.40-4.21 \%)$ & & \\
\hline 1998 & $81.37 \%$ & (79.03-83.70\%) & $13.16 \%$ & $(11.03-15.30 \%)$ & $0.59 \%$ & $(0.35-0.83 \%)$ & $4.87 \%$ & $(3.65-6.10 \%)$ & & \\
\hline 1999 & $82.28 \%$ & (79.81-84.75\%) & $13.25 \%$ & (10.68-15.82\%) & $1.13 \%$ & (0.53-1.73\%) & $3.34 \%$ & (2.59-4.09\%) & & \\
\hline 2000 & $83.03 \%$ & (80.64-85.42\%) & $12.97 \%$ & (10.60-15.33\%) & $0.55 \%$ & $(0.31-0.79 \%)$ & $3.45 \%$ & $(2.62-4.29 \%)$ & & \\
\hline 2001 & $80.11 \%$ & $(78.47-81.75 \%)$ & $12.16 \%$ & (10.54-13.77\%) & $1.01 \%$ & $(0.67-1.36 \%)$ & $3.95 \%$ & $(3.19-4.71 \%)$ & $1.30 \%$ & $(1.03-1.58 \%)$ \\
\hline 2002 & $81.40 \%$ & (79.83-82.96\%) & $12.34 \%$ & $(10.87-13.81 \%)$ & $0.79 \%$ & (0.53-1.05\%) & $3.94 \%$ & $(3.15-4.72 \%)$ & $0.27 \%$ & $(0.14-0.40 \%)$ \\
\hline 2003 & $80.85 \%$ & (79.09-82.61\%) & $12.47 \%$ & $(10.79-14.15 \%)$ & $0.64 \%$ & $(0.36-0.92 \%)$ & $3.96 \%$ & $(3.21-4.71 \%)$ & $0.34 \%$ & $(0.15-0.52 \%)$ \\
\hline 2004 & $80.28 \%$ & (78.34-82.23\%) & $12.44 \%$ & (10.68-14.19\%) & $0.81 \%$ & $(0.48-1.14 \%)$ & $4.25 \%$ & (3.39-5.12\%) & $0.37 \%$ & $(0.16-0.57 \%)$ \\
\hline 2005 & $80.30 \%$ & (78.39-82.20\%) & $12.39 \%$ & $(10.76-14.02 \%)$ & $0.78 \%$ & $(0.41-1.15 \%)$ & $4.38 \%$ & $(3.51-5.25 \%)$ & $0.34 \%$ & (0.08-0.60\%) \\
\hline 2006 & $80.18 \%$ & (78.48-81.87\%) & $12.41 \%$ & $(11.02-13.80 \%)$ & $0.91 \%$ & $(0.52-1.30 \%)$ & $4.32 \%$ & $(3.48-5.16 \%)$ & $0.44 \%$ & $(0.19-0.70 \%)$ \\
\hline 2007 & $80.50 \%$ & (78.44-82.57\%) & $12.31 \%$ & $(10.52-14.11 \%)$ & $0.79 \%$ & $(0.46-1.12 \%)$ & $4.28 \%$ & $(3.44-5.11 \%)$ & $0.21 \%$ & $(0.11-0.31 \%)$ \\
\hline 2008 & $79.87 \%$ & (78.08-81.66\%) & $12.43 \%$ & (11.02-13.84\%) & $0.78 \%$ & $(0.41-1.15 \%)$ & $4.54 \%$ & $(3.71-5.37 \%)$ & $0.25 \%$ & $(0.11-0.40 \%)$ \\
\hline 2009 & $79.88 \%$ & (78.13-81.63\%) & $12.54 \%$ & (10.98-14.09\%) & $0.90 \%$ & $(0.44-1.36 \%)$ & $4.66 \%$ & $(3.77-5.55 \%)$ & $0.29 \%$ & $(0.15-0.43 \%)$ \\
\hline 2010 & $79.56 \%$ & (77.57-81.56\%) & $12.29 \%$ & (10.74-13.84\%) & $0.81 \%$ & $(0.30-1.32 \%)$ & $4.96 \%$ & $(3.92-5.99 \%)$ & $0.68 \%$ & $(0.36-1.00 \%)$ \\
\hline 2011 & $79.89 \%$ & (78.00-81.77\%) & $12.39 \%$ & (11.01-13.77\%) & $0.01 \%$ & $-(0.01-0.03 \%)$ & $5.14 \%$ & $(4.00-6.29 \%)$ & $0.01 \%$ & $-(0.01-0.02 \%)$ \\
\hline All & $80.82 \%$ & (80.07-81.58\%) & $12.60 \%$ & $(11.91-13.29 \%)$ & $0.79 \%$ & $(0.66-0.92 \%)$ & $4.21 \%$ & $(3.88-4.55 \%)$ & $0.29 \%$ & $(0.23-0.34 \%)$ \\
\hline
\end{tabular}

The category of "multiple races" was introduced in 2001

${ }^{*} p<0.001$. 


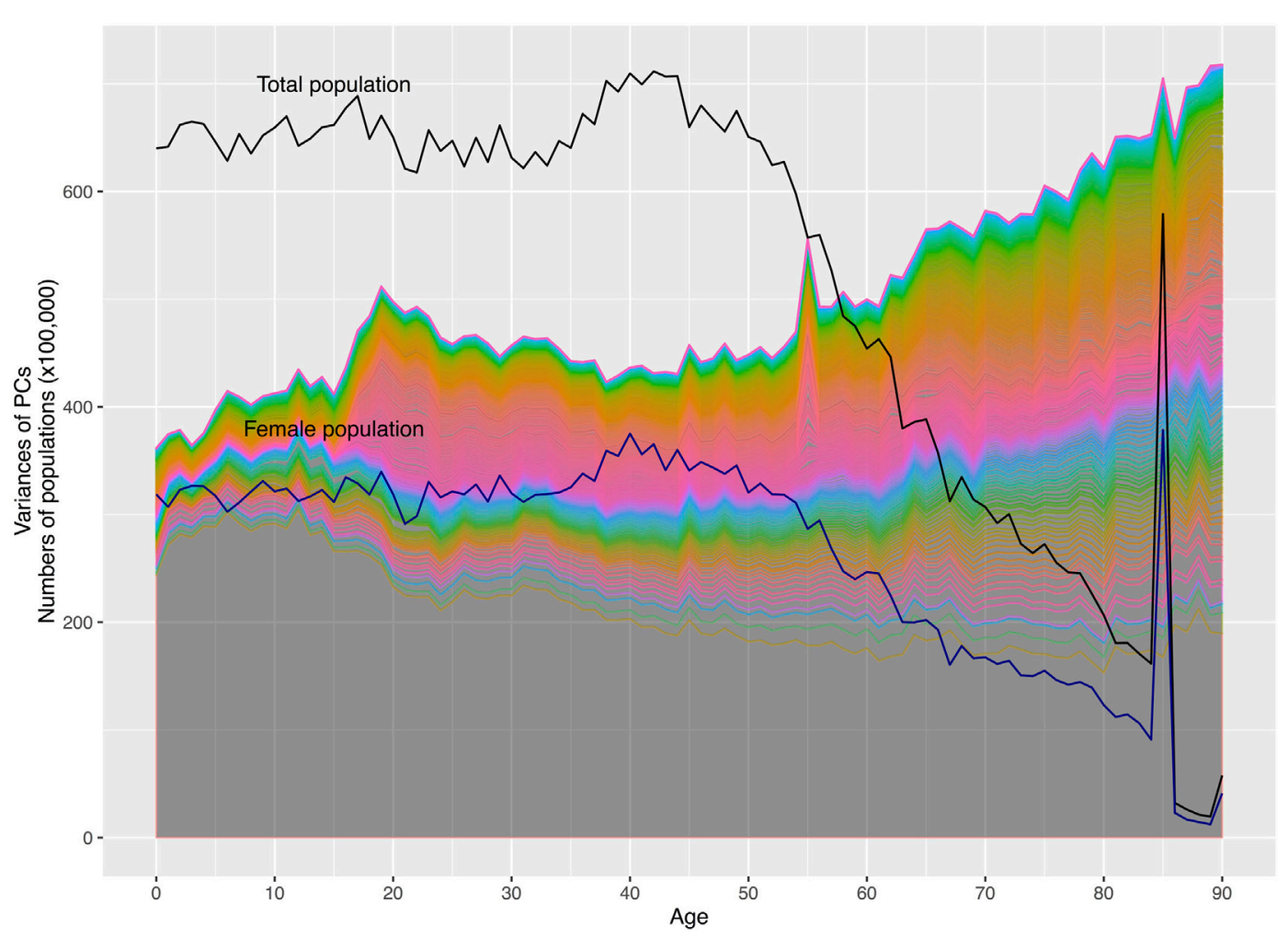

FIGURE 2 | The numbers of population and variances of principal components (PCs) by age. Note: the area under the first lowest curve represents the variance of the first principal component (PC1); the area between the first and second lowest curves represents the variance of the second PC (PC2); this principle applies to other areas under curves. There are 525 PCs in the graph. The upper black solid line represents the numbers of total populations by age; the lower represents the numbers of female populations. The spikes of population numbers at age 85 are due to the top censoring of age beginning in 2000 .

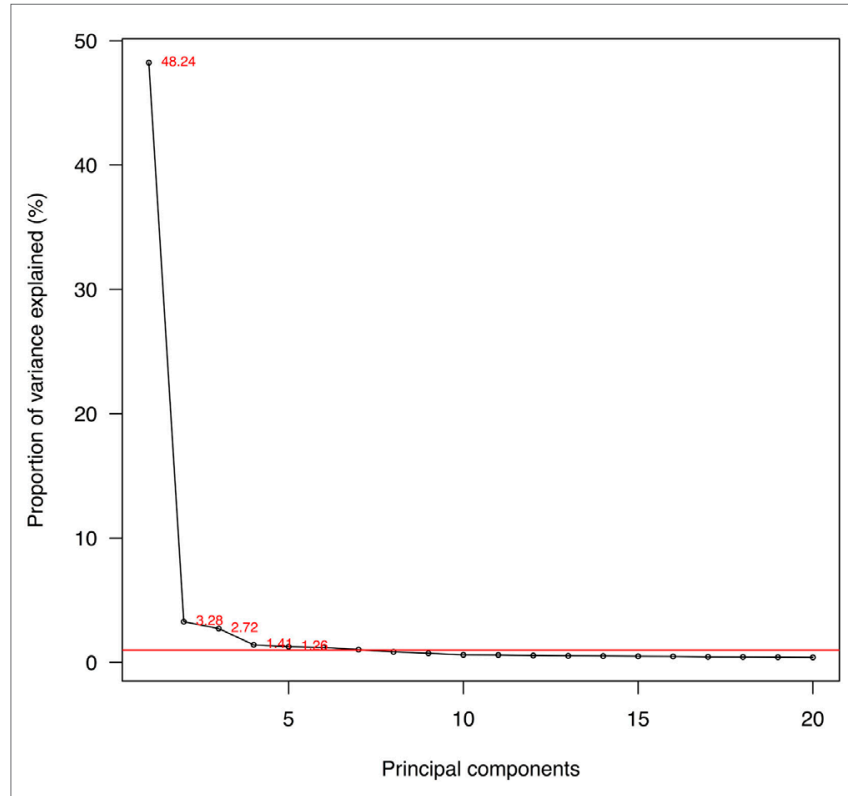

FIGURE 3 | Proportions of variances explained by the first 20 principal components (PCs). Note: red line: 1\% of total variance; 525 PCs in total. each age category (35). The beginning and the end ages of life stages could serve as references for the age stratification, if there is no empirical evidence or prior knowledge about the population under investigation. Our results provide an alternative choice of selecting age cutoffs, especially for those who lack empirical evidence to stratify age groups or information on the stages of life in social and health data.

Fourth, the application of life staging might be an important method to understand the sources of variability in the dataset, while PCA is recommended as the first step to explore the information observed, especially for complex data (36). This is increasingly important while we observe that there are many variables contributing high proportions of their own variances to PC1, but might not be frequently used for empirical research (see Tables 2-5 for the leading variables). This highlights a potential problem of information underuse and a lack of comprehensive understanding of the life course in aging and social data. This problem is particularly acute when many researchers adopt a uni-dimensional view of trajectories across certain stages of life $(3,6,37)$ or propose multiple trajectories without summarizing them (38). This study aims to be the first to call attention to the potential of underused measurements in existing surveys. 
TABLE 2 | The contribution of variance of each variable to PCs, sorted by the values in the first five PCs.

\begin{tabular}{|c|c|c|c|c|c|c|}
\hline Variables & Labels & PC1 & PC2 & PC3 & PC4 & PC5 \\
\hline hhnwcpy 1 & HOME HLTH NON-AGNCY-WORKERS COMP AMT 11 & 0.993 & 0.003 & 0.000 & 0.000 & 0.000 \\
\hline dvowcpy 1 & ORTHODONTIST VISITS-WORKERS COMP AMT 11 & 0.993 & 0.003 & 0.000 & 0.000 & 0.000 \\
\hline zidosry1 & ZERO-NITE IP STAZ-UNCLAS SRCE AMT-DR 11 & 0.992 & 0.003 & 0.000 & 0.000 & 0.000 \\
\hline hhnofdy1 & HOME HLTH NON-AGNCY-OTHR FED AMT 11 & 0.992 & 0.003 & 0.000 & 0.000 & 0.000 \\
\hline obewcpy1 & OPTOMETRIST OFF VSTS-WORKERS COMP AMT 11 & 0.991 & 0.003 & 0.000 & 0.000 & 0.000 \\
\hline zidvay1 & ZERO-NITE IP STAZ-VA/CHAMPVA AMT-DR 11 & 0.991 & 0.003 & 0.000 & 0.000 & 0.000 \\
\hline zidstly1 & ZERO-NITE IP STAZ-OTH ST/LOC AMT-DR 11 & 0.991 & 0.003 & 0.000 & 0.000 & 0.000 \\
\hline hhnopuy1 & HOME HLTH NON-AGNCY-OTH PUBLIC AMT 11 & 0.991 & 0.003 & 0.000 & 0.000 & 0.000 \\
\hline obcopuy 1 & CHIRO OFF VISTS-OTHR PUBLIC AMT 11 & 0.991 & 0.003 & 0.000 & 0.000 & 0.000 \\
\hline dvomery1 & ORTHODONTIST VISITS-MEDICARE AMT 11 & 0.991 & 0.003 & 0.000 & 0.000 & 0.000 \\
\hline obcofdy1 & CHIRO OFF VISITS-OTHER FEDERAL AMT 11 & 0.991 & 0.003 & 0.000 & 0.000 & 0.000 \\
\hline zifstly1 & ZERO-NITE IP STAZ-OTH ST/LOC AMT-FAC 11 & 0.990 & 0.003 & 0.000 & 0.000 & 0.000 \\
\hline erdofdy1 & ER-OTHER FED AMT-DR 11 & 0.990 & 0.003 & 0.000 & 0.000 & 0.000 \\
\hline dvoopuy1 & ORTHODONTIST VISITS-OTHR PUBLIC AMT 11 & 0.990 & 0.003 & 0.000 & 0.000 & 0.000 \\
\hline zifopuy1 & ZERO-NITE IP STAZ-OTH PUBLIC AMT-FAC 11 & 0.990 & 0.003 & 0.000 & 0.000 & 0.000 \\
\hline viswcpy 1 & GLASSES/CNTCT LENSES-WORKERS COMP AMT 11 & 0.990 & 0.003 & 0.000 & 0.000 & 0.000 \\
\hline dvoofdy1 & ORTHODONTIST VISITS-OTHR FED AMT 11 & 0.990 & 0.003 & 0.000 & 0.000 & 0.000 \\
\hline dvovay1 & ORTHODONTIST VISITS-VA/CHAMPVA AMT 11 & 0.990 & 0.003 & 0.000 & 0.000 & 0.000 \\
\hline zidopuy1 & ZERO-NITE IP STAZ-OTH PUBLIC AMT-DR 11 & 0.989 & 0.003 & 0.000 & 0.000 & 0.000 \\
\hline zifofdy 1 & ZERO-NITE IP STAZ-OTHER FED AMT-FAC 11 & 0.989 & 0.003 & 0.000 & 0.000 & 0.000 \\
\hline obaopuy 1 & PHYS ASS T OFF VSTS-OTH PUBLIC AMT 11 & 0.989 & 0.003 & 0.000 & 0.000 & 0.000 \\
\hline opsofdy 1 & OPD DR VISITS-OTHER FED AMT-DR 11 & 0.989 & 0.003 & 0.000 & 0.000 & 0.000 \\
\hline hhnvay1 & HOME HLTH NON-AGNCY-VA/CHAMPVA AMT 11 & 0.988 & 0.003 & 0.000 & 0.000 & 0.000 \\
\hline zifosry1 & ZERO-NITE IP STAZ-UNCLAS SRCE AMT-FAC 11 & 0.988 & 0.003 & 0.000 & 0.000 & 0.000 \\
\hline opposry1 & OPD NON-DR VSTS-OT UNCLAS SRC AMT-DR 11 & 0.988 & 0.003 & 0.000 & 0.000 & 0.000 \\
\hline obtopuy1 & PT/OT OFF VISITS-OTH PUBLIC AMT 11 & 0.988 & 0.003 & 0.000 & 0.000 & 0.000 \\
\hline hhnosry1 & H HLTH NON-AGNCY-OT UNCLASS SRCE AMT 11 & 0.988 & 0.003 & 0.000 & 0.000 & 0.000 \\
\hline obcstly1 & CHIRO OFF VISITS-OTH ST/LOCAL AMT 11 & 0.987 & 0.003 & 0.000 & 0.000 & 0.000 \\
\hline obeopuy1 & OPTOMETRIST OFF VSTS-OTH PUBLIC AMT 11 & 0.987 & 0.003 & 0.000 & 0.000 & 0.000 \\
\hline hhawcpy1 & HOME HLTH AGENCY - WORKERS COMP AMT 11 & 0.987 & 0.003 & 0.000 & 0.000 & 0.000 \\
\hline oppstly1 & OPD NON-DR VISITS-OTH ST/LOC AMT-DR 11 & 0.987 & 0.003 & 0.000 & 0.000 & 0.000 \\
\hline zidwcpy1 & ZERO-NITE IP STAZ-WRKERS COMP AMT-DR 11 & 0.986 & 0.003 & 0.000 & 0.000 & 0.000 \\
\hline hhnopry1 & HOME HLTH NON-AGNCY-OTH PRIVATE AMT 11 & 0.985 & 0.003 & 0.000 & 0.000 & 0.000 \\
\hline zifwcpy1 & ZERO-NITE IP STAZ-WRKERS COMP AMT-FAC 11 & 0.985 & 0.003 & 0.000 & 0.000 & 0.000 \\
\hline oppofdy1 & OPD NON-DR VISITS-OTHER FED AMT-DR 11 & 0.984 & 0.003 & 0.000 & 0.000 & 0.000 \\
\hline obeofdy1 & OPTOMETRIST OFF VSTS-OTH FEDERAL AMT 11 & 0.984 & 0.003 & 0.000 & 0.000 & 0.000 \\
\hline othopuy1 & OTHER EQUP/SUPPLY - OTH PUBLIC AMT 11 & 0.984 & 0.003 & 0.000 & 0.000 & 0.000 \\
\hline obtofdy1 & PT/OT OFF VISITS-OTHER FED AMT 11 & 0.983 & 0.003 & 0.000 & 0.000 & 0.000 \\
\hline hhnstly1 & HOME HLTH NON-AGNCY-OTHR ST/LOCL AMT 11 & 0.983 & 0.003 & 0.000 & 0.000 & 0.000 \\
\hline zifvay1 & ZERO-NITE IP STAZ-VA/CHAMPVA AMT-FAC 11 & 0.982 & 0.003 & 0.000 & 0.000 & 0.000 \\
\hline
\end{tabular}

PC, principal component.

The numbers after the "." in the variable names indicating the categories. Other variables not shown for limited space. The range of contribution of variable variance is from 0 (no variance contributed to $P C s$ ) to 1 (all of variable variance contributed).

Fifth, this data-driven approach also identified that the first PC seem to be related to and can be approximated with similar input variables, such as health insurance categories. This is useful for epidemiologists or data scientists, who aim to construct indexes that explain a large portion of the overall variance in the data set. We showed that this line of research may be feasible with major national surveys. We are developing this method as a strategy to systematically understand large datasets. Sixth, certain life stages might be important for the future research to understand the cause of decline or incline across a life course, such as the stages of transition identified with PC1 and PC2 values. We will focus on the life stages with significant transitions and search for a possible mechanism of these fluctuations.

\section{Limitations}

There are several limitations to this study. First, the MEPS dataset is implemented in the US with a focus on the health coverage and related issues (16). Other datasets or surveys may focus on other topics, concentrate on certain age groups or are created in distinctive manners, such as in other jurisdictions or 
TABLE 3 | The contribution of variance of each variable to the second principal component, sorted by the contributed variance of variables in the second principal component.

\begin{tabular}{|c|c|c|c|c|c|c|}
\hline Variables & Labels & PC1 & PC2 & PC3 & PC4 & PC5 \\
\hline pubjay1x.1 & COVR BY ANY PUBLIC INS IN JAN11 (ED) & 0.001 & 0.563 & 0.024 & 0.036 & 0.004 \\
\hline pubdey1x.1 & COVR BY ANY PUBLIC INS IN DEC11 (ED) & 0.001 & 0.540 & 0.028 & 0.044 & 0.002 \\
\hline mcrdey $1 x .1$ & COVERED BY MEDICARE IN DEC11 (ED) & 0.017 & 0.516 & 0.035 & 0.006 & 0.002 \\
\hline obdmcry1 & DR OFFICE VISITS-MEDICARE AMT 11 & 0.030 & 0.492 & 0.051 & 0.006 & 0.002 \\
\hline ssecpy $1 x$ & PERSON'S SOCIAL SECURITY INCOME 11 & 0.003 & 0.428 & 0.040 & 0.010 & 0.001 \\
\hline empst1.4 & EMPLOYMENT STATUS RD 1 & 0.019 & 0.408 & 0.000 & 0.005 & 0.008 \\
\hline evrwrky1.1 & EVER WRKD FOR PAY IN LIFE AS OF 12/31/11 & 0.016 & 0.391 & 0.021 & 0.003 & 0.005 \\
\hline actlim1.1 & ANY LIMITATION WORK/HOUSEWRK/SCHL-RD 1 & 0.002 & 0.354 & 0.010 & 0.020 & 0.073 \\
\hline wlklim1.1 & LIMITATION IN PHYSICAL FUNCTIONING-RD1 & 0.007 & 0.348 & 0.043 & 0.034 & 0.047 \\
\hline anylimy1.1 & ANY LIMITATION IN P15R3,4,5/P16R1,2,3 11 & 0.025 & 0.348 & 0.052 & 0.043 & 0.034 \\
\hline pubdey $1 \times .2$ & COVR BY ANY PUBLIC INS IN DEC11 (ED) & 0.356 & 0.347 & 0.019 & 0.026 & 0.004 \\
\hline pubjay $1 \times .2$ & COVR BY ANY PUBLIC INS IN JAN11 (ED) & 0.357 & 0.330 & 0.022 & 0.028 & 0.004 \\
\hline inscovy 1.2 & HEALTH INSURANCE COVERAGE INDICATOR 11 & 0.005 & 0.323 & 0.170 & 0.038 & 0.018 \\
\hline fngrdf1 & DIFFICULTY USING FINGERS TO GRASP-RD 1 & 0.123 & 0.299 & 0.034 & 0.031 & 0.055 \\
\hline mcrdey $1 x .2$ & COVERED BY MEDICARE IN DEC11 (ED) & 0.410 & 0.293 & 0.021 & 0.005 & 0.000 \\
\hline unable1.1 & COMPLETELY UNABLE TO DO ACTIVITY-RD 1 & 0.000 & 0.276 & 0.003 & 0.011 & 0.072 \\
\hline aidhlp1.1 & USED ASSISTIVE DEVICES-RD 1 & 0.002 & 0.272 & 0.014 & 0.015 & 0.051 \\
\hline $\mathrm{nwk} 1.2$ & REASON NOT WORKING DURING RD 1 & 0.016 & 0.246 & 0.041 & 0.000 & 0.014 \\
\hline iadlhp1.1 & IADL SCREENER-RD 1 & 0.001 & 0.222 & 0.003 & 0.010 & 0.085 \\
\hline stjbyy1 & YEAR STARTED RD 1 CMJ & 0.101 & 0.222 & 0.131 & 0.160 & 0.057 \\
\hline anylimy 1.2 & ANY LIMITATION IN P15R3,4,5/P16R1,2,3 11 & 0.314 & 0.220 & 0.038 & 0.033 & 0.028 \\
\hline rxmcry1 & TOTAL RX-MEDICARE AMT 11 & 0.087 & 0.217 & 0.012 & 0.004 & 0.000 \\
\hline evretiy 1.1 & PERSON HAS EVER RETIRED 11 & 0.018 & 0.214 & 0.059 & 0.002 & 0.008 \\
\hline iadlhp2.1 & IADL SCREENER-RD 2 & 0.001 & 0.212 & 0.003 & 0.009 & 0.071 \\
\hline soclim1.1 & SOCIAL LIMITATIONS-RD 1 & 0.002 & 0.207 & 0.009 & 0.013 & 0.059 \\
\hline rxtoty1 & \# PRESC MEDS INCL REFILLS 11 & 0.010 & 0.206 & 0.197 & 0.002 & 0.003 \\
\hline retpln1 & PENSION PLAN AT RD 1 CMJ & 0.015 & 0.199 & 0.089 & 0.160 & 0.059 \\
\hline retpln2 & PENSION PLAN AT RD 2 CMJ & 0.015 & 0.195 & 0.077 & 0.155 & 0.053 \\
\hline empst1.1 & EMPLOYMENT STATUS RD 1 & 0.197 & 0.192 & 0.117 & 0.140 & 0.050 \\
\hline pegjay1.2 & COVERED BY EMPL UNION INS IN JAN11 & 0.008 & 0.188 & 0.300 & 0.137 & 0.040 \\
\hline pegdey 1.2 & COVERED BY EMPL UNION INS IN DEC11 & 0.006 & 0.187 & 0.315 & 0.120 & 0.049 \\
\hline opfmcry1 & ALL OPD VISITS-MEDICARE AMT-FAC 11 & 0.164 & 0.185 & 0.060 & 0.001 & 0.072 \\
\hline nwk1.3 & REASON NOT WORKING DURING RD 1 & 0.000 & 0.182 & 0.001 & 0.006 & 0.031 \\
\hline obomcry1 & NON-DR OFF VISTS-MEDICARE AMT 11 & 0.136 & 0.176 & 0.038 & 0.003 & 0.007 \\
\hline coglim1.1 & COGNITIVE LIMITATIONS-RD 1 & 0.001 & 0.172 & 0.002 & 0.010 & 0.056 \\
\hline marryy $1 x .2$ & MARITAL STATUS-12/31/11 (EDITED/IMPUTED) & 0.005 & 0.166 & 0.010 & 0.009 & 0.001 \\
\hline held2x.1 & HEALTH INSUR HELD FROM RD 2 CMJ (ED) & 0.105 & 0.145 & 0.223 & 0.000 & 0.177 \\
\hline ipfmcry1 & IP HOSP STAZ-MEDICARE AMT-FAC 11 & 0.154 & 0.143 & 0.017 & 0.006 & 0.005 \\
\hline held1x.1 & HEALTH INSUR HELD FROM RD 1 CMJ (ED) & 0.103 & 0.141 & 0.230 & 0.001 & 0.177 \\
\hline totmcdy 1 & TOTAL AMT PAID BY MEDICAID 11 & 0.112 & 0.140 & 0.107 & 0.095 & 0.042 \\
\hline
\end{tabular}

PC, principal component.

The numbers after the "." in the variable names indicating the categories. Other variables not shown for limited space. The range of contribution of variable variance is from 0 (no variance contributed to $P C s$ ) to 1 (all of variable variance contributed).

under different policies. Individual health coverage and healthcare utilization could also be influenced by public policies. For example, the Affordable Care Act sought to increase health coverage and improve access to health care (39). Therefore, the PCA analysis results with the MEPS dataset may not be able to be extrapolated.

The second limitation is also related to the contexts. The detailed data on life stages help us to have a better understanding of the ages of transitions across life course. However, the PCA results are influenced by how and what data are collected in different age groups. The sum of all variances between individuals depends on the variable variances that are directly influenced by the numbers of measures on similar characteristics and measurement scales (continuous or categorical). For example, the questionnaire of the Children with Special Health Care Needs in the MEPS is applicable to those ages of 0-17 years, 
TABLE 4 | The contribution of variance of each variable to the third principal component, sorted by the contributed variance of variables in the third principal component.

\begin{tabular}{|c|c|c|c|c|c|c|}
\hline Variables & Labels & PC1 & PC2 & РC3 & PC4 & PC5 \\
\hline totprvy1 & TOTAL AMT PAID BY PRIVATE INS 11 & 0.162 & 0.028 & 0.420 & 0.092 & 0.000 \\
\hline obdprvy1 & DR OFFICE VISITS-PRIVATE INS AMT 11 & 0.068 & 0.010 & 0.334 & 0.078 & 0.002 \\
\hline rxprvy1 & TOTAL RX-PRIVATE INS AMT 11 & 0.029 & 0.008 & 0.331 & 0.032 & 0.001 \\
\hline hpejay 1.1 & HOLDER OF EMPL UNION INS IN JAN11 & 0.120 & 0.071 & 0.318 & 0.002 & 0.159 \\
\hline pegdey 1.2 & COVERED BY EMPL UNION INS IN DEC11 & 0.006 & 0.187 & 0.315 & 0.120 & 0.049 \\
\hline hpedey1.1 & HOLDER OF EMPL UNION INS IN DEC11 & 0.125 & 0.082 & 0.304 & 0.001 & 0.159 \\
\hline pegjay1.2 & COVERED BY EMPL UNION INS IN JAN11 & 0.008 & 0.188 & 0.300 & 0.137 & 0.040 \\
\hline hpedey1.2 & HOLDER OF EMPL UNION INS IN DEC11 & 0.116 & 0.086 & 0.293 & 0.000 & 0.175 \\
\hline hpejay1.2 & HOLDER OF EMPL UNION INS IN JAN11 & 0.120 & 0.088 & 0.274 & 0.004 & 0.156 \\
\hline opfprvy1 & ALL OPD VISITS-PRIV INS AMT-FAC 11 & 0.027 & 0.008 & 0.271 & 0.019 & 0.219 \\
\hline pegjay1.1 & COVERED BY EMPL UNION INS IN JAN11 & 0.273 & 0.118 & 0.248 & 0.096 & 0.028 \\
\hline totslfy1 & TOTAL AMT PAID BY SELF/FAMILY 11 & 0.219 & 0.046 & 0.234 & 0.000 & 0.002 \\
\hline pegdey1.1 & COVERED BY EMPL UNION INS IN DEC11 & 0.282 & 0.132 & 0.234 & 0.096 & 0.028 \\
\hline held1x.1 & HEALTH INSUR HELD FROM RD 1 CMJ (ED) & 0.103 & 0.141 & 0.230 & 0.001 & 0.177 \\
\hline oboprvy1 & NON-DR OFF VISTS-PRIVATE INS AMT 11 & 0.000 & 0.000 & 0.225 & 0.016 & 0.003 \\
\hline held2x.1 & HEALTH INSUR HELD FROM RD 2 CMJ (ED) & 0.105 & 0.145 & 0.223 & 0.000 & 0.177 \\
\hline opdprvy1 & ALL OPD VISITS-PRIV INS AMT-DR 11 & 0.085 & 0.007 & 0.211 & 0.014 & 0.226 \\
\hline obdslfy1 & DR OFFICE VISITS-SELF/FAMILY AMT 11 & 0.053 & 0.001 & 0.204 & 0.006 & 0.011 \\
\hline mcddey1.1 & COV BY MEDICAID OR SCHIP IN DEC11 & 0.016 & 0.111 & 0.201 & 0.144 & 0.030 \\
\hline opdexpy1 & TOTAL OUTPATIENT PROVIDER EXP 11 & 0.053 & 0.066 & 0.201 & 0.006 & 0.275 \\
\hline rxtoty1 & \# PRESC MEDS INCL REFILLS 11 & 0.010 & 0.206 & 0.197 & 0.002 & 0.003 \\
\hline pridey 1 & COVERED BY PRIVATE INS IN DEC11 & 0.287 & 0.071 & 0.193 & 0.054 & 0.018 \\
\hline mcdjay1.1 & COV BY MEDICAID OR SCHIP IN JAN11 & 0.015 & 0.107 & 0.185 & 0.133 & 0.032 \\
\hline marryy $1 x .6$ & MARITAL STATUS-12/31/11 (EDITED/IMPUTED) & 0.004 & 0.003 & 0.183 & 0.331 & 0.035 \\
\hline inscovy 1.2 & HEALTH INSURANCE COVERAGE INDICATOR 11 & 0.005 & 0.323 & 0.170 & 0.038 & 0.018 \\
\hline optotvy1 & \# OUTPATIENT DEPT PROVIDER VISITS 11 & 0.259 & 0.076 & 0.168 & 0.003 & 0.167 \\
\hline opoprvy1 & OPD NON-DR VISITS-PRIV INS AMT-FAC 11 & 0.087 & 0.005 & 0.166 & 0.009 & 0.118 \\
\hline intrpy $1 \mathrm{x}$ & PERSON'S INTEREST INCOME 11 & 0.014 & 0.007 & 0.165 & 0.004 & 0.000 \\
\hline opoexpy1 & TOTAL OUTPATIENT NON-DR_FAC EXP 11 & 0.049 & 0.063 & 0.159 & 0.002 & 0.141 \\
\hline wrglas 2.2 & WEARS EYEGLASSES OR CONTACTS-RD 2 & 0.054 & 0.042 & 0.158 & 0.020 & 0.007 \\
\hline obothvy1 & \# OFFICE-BASED NON-PHYSICAN VISITS 11 & 0.041 & 0.035 & 0.158 & 0.001 & 0.004 \\
\hline opvprvy1 & OPD DR VISITS-PRIV INS AMT-FAC 11 & 0.088 & 0.003 & 0.147 & 0.012 & 0.149 \\
\hline wrglas 2.1 & WEARS EYEGLASSES OR CONTACTS-RD 2 & 0.162 & 0.046 & 0.143 & 0.017 & 0.004 \\
\hline oboslfy1 & NON-DR OFF VISTS - SELF/FAMILY AMT 11 & 0.002 & 0.001 & 0.136 & 0.000 & 0.007 \\
\hline obdtchy1 & OFFICE-BASED PHYSICIAN VISIT CHARGES 11 & 0.099 & 0.109 & 0.136 & 0.044 & 0.000 \\
\hline coglim1.2 & COGNITIVE LIMITATIONS-RD 1 & 0.305 & 0.002 & 0.134 & 0.194 & 0.007 \\
\hline stjbyy1 & YEAR STARTED RD 1 CMJ & 0.101 & 0.222 & 0.131 & 0.160 & 0.057 \\
\hline taxfrmy1.1 & TAX FORM PERSON WILL FILE 11 & 0.078 & 0.003 & 0.131 & 0.012 & 0.002 \\
\hline insjay1x.2 & COVR BY HOSP/MED INS IN JAN11 (ED) & 0.003 & 0.014 & 0.128 & 0.390 & 0.067 \\
\hline insdey $1 \times .2$ & COVR BY HOSP/MED INS IN DEC11 (ED) & 0.003 & 0.015 & 0.127 & 0.393 & 0.074 \\
\hline
\end{tabular}

PC, principal component.

The numbers after the "." in the variable names indicating the categories. Other variables not shown for limited space. The range of contribution of variable variance is from 0 (no variance contributed to PCs) to 1 (all of variable variance contributed).

although not selected for this study (22). In addition, the MEPS only surveys non-institutionalized civilians and it is unclear how this may affect the results. By recognizing these limitations, caution would be necessary for those life stages identified due to questionnaire changes, rather than transitions in the life course.

Third, there might be some questionnaire modifications introduced between 1996 and 2011 that we are not aware of. We have read through various documentation to accommodate modifications in racial categories and other variable definitions (22). However, we cannot guarantee that all questionnaire revisions are reflected in the data processing. Fourth, the cross-sectional nature of the MEPS makes it possible to have data on individuals from the whole age spectrum and illustrate trajectories across life course. However, individual trajectories are followed-up for only 2 years. It remains uncertain whether the population trajectories of mean PC values can reflect individual ones. 


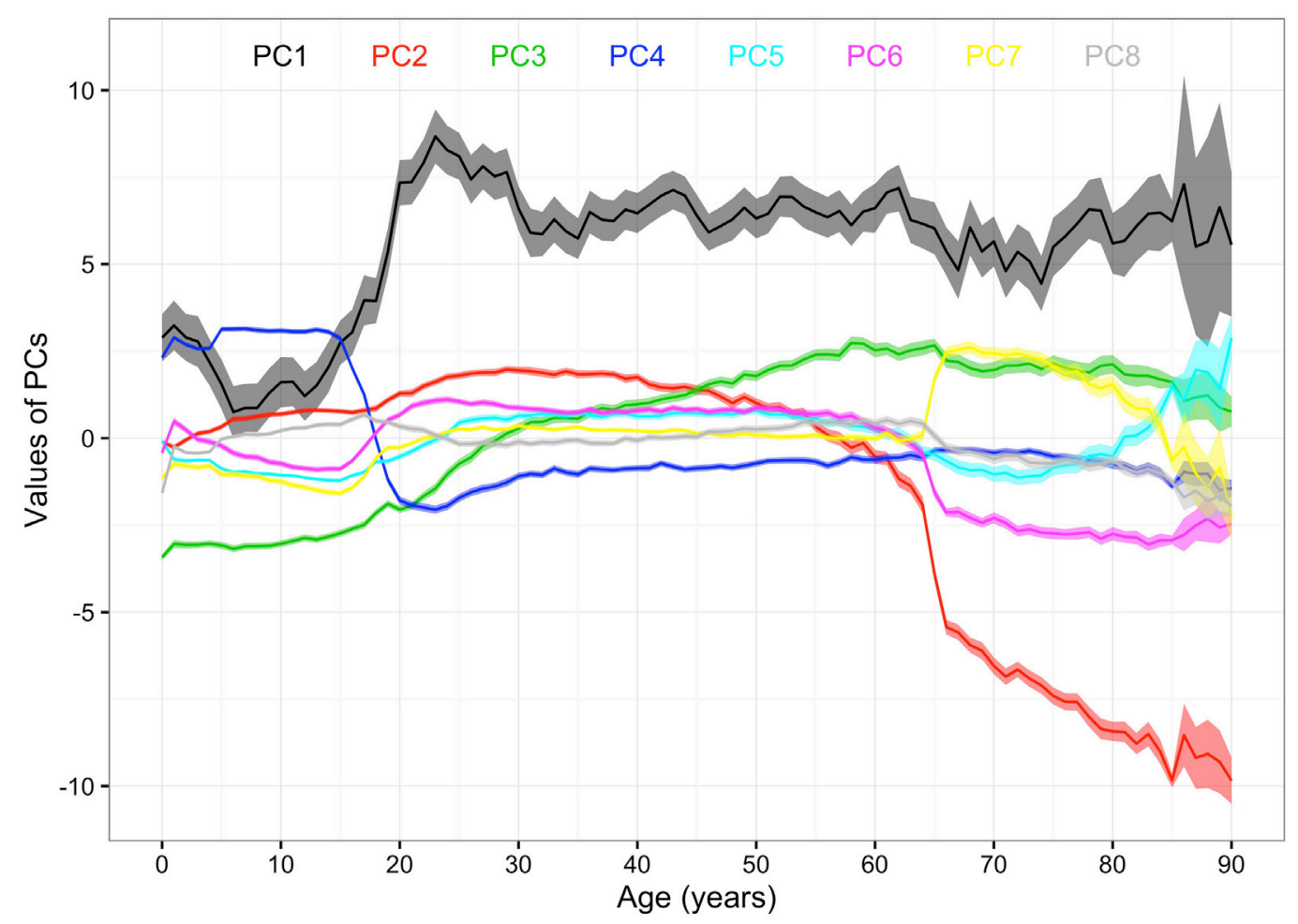

FIGURE 4 | Mean values of the first to the eighth principal components (PCs) by age. Note: 95\% Cls of the PCs are the ranges of the same colors as the PCs. The colors and corresponding numbers of PCs are labeled on the graph.

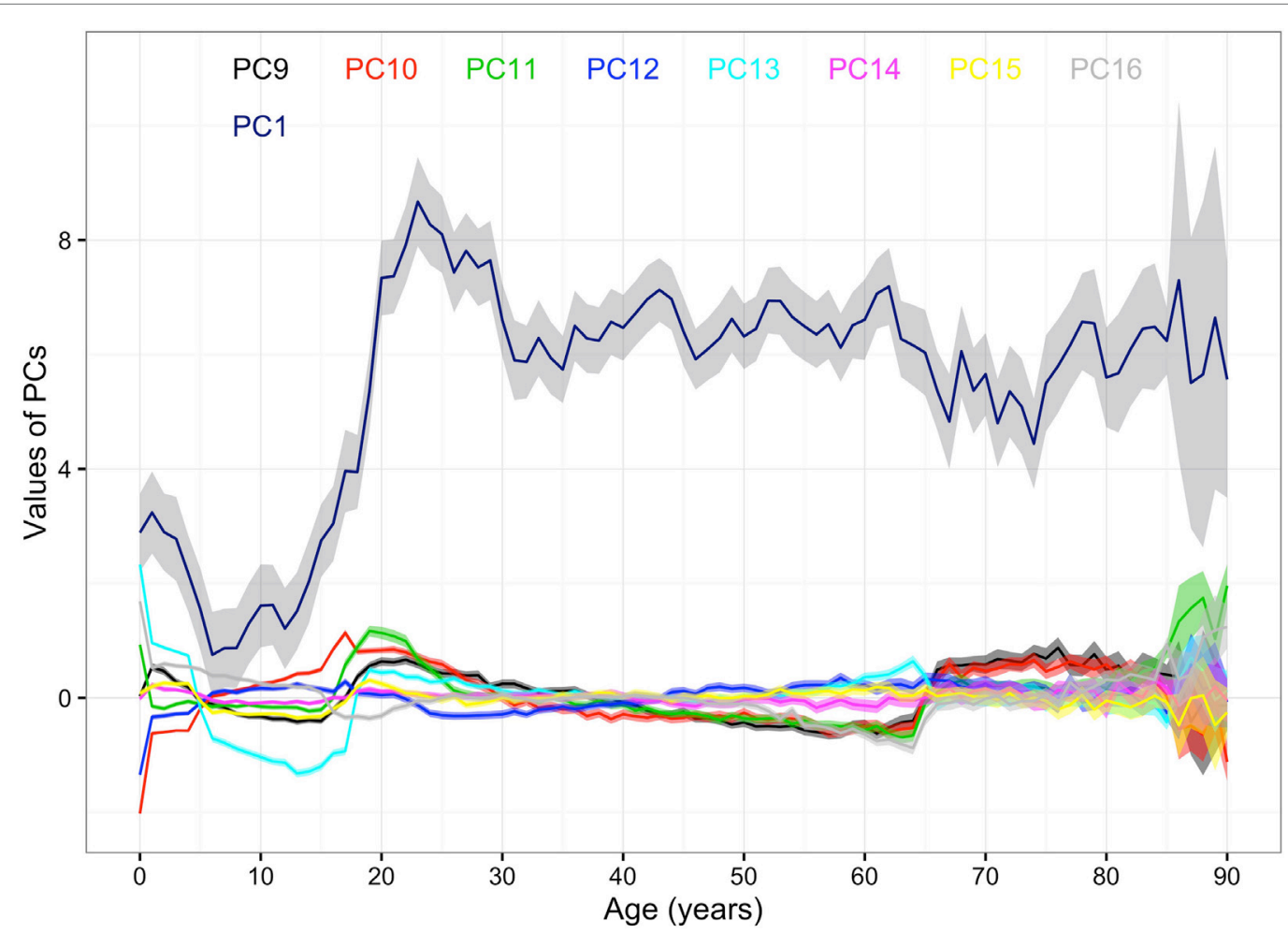

FIGURE 5 | Mean values of the 1st and the 9th-16th principal components (PCs) by age. Note: 95\% Cls of the PCs are the ranges of the same colors as the PCs. The color of first PC is navy blue. The colors and corresponding numbers of PCs are labeled on the graph. 
Fifth, the trajectories might be partly caused by the social or health policies that aim to improve population literacy or income security, such as compulsory education for children and retirement arrangements before 65 years of age. This confounding factor needs a separate study. Sixth, adjusting the complex survey design is important for maintaining national representativeness,

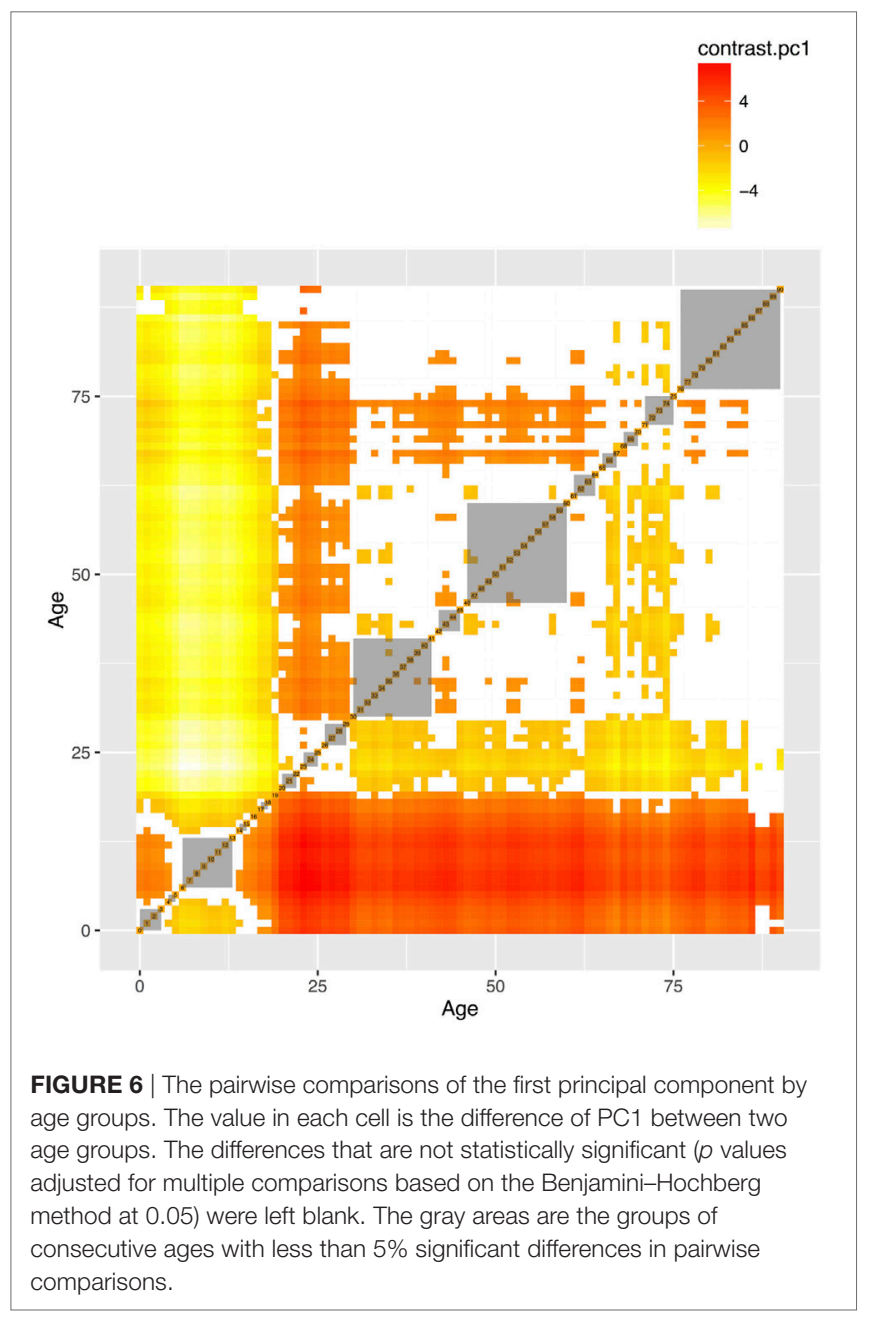

but this leaves fewer choices of analytical tools. For example, to the best of our knowledge, there is only linear PCA available for datasets with complex survey design and no tool to implement the correlation-based feature selection process after taking the survey design into account (25). Non-linear or other types of PCA that some researchers propose for categorical variables are

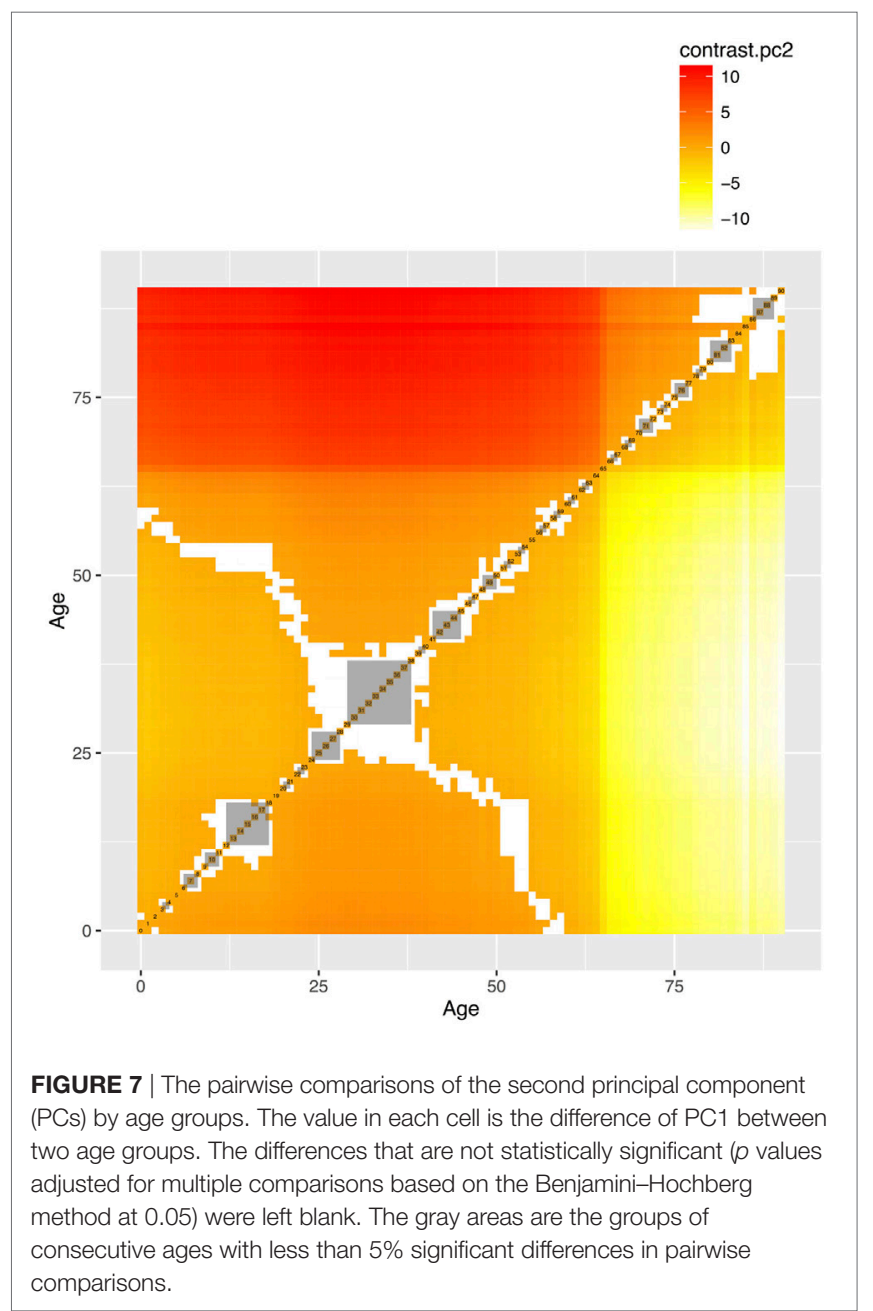

TABLE $5 \mid$ R squared of the leading variables that best explained first principal component.

\begin{tabular}{|c|c|c|c|c|c|}
\hline Variables & Labels & PC1 & PC2 & PC3 & PC4 \\
\hline povcaty1 & FAMLY INC AS \% OF POVERTY LINE-CATEGO 11 & 0.243 & 0.017 & 0.032 & 0.002 \\
\hline marryy $1 x .3$ & MARITAL STATUS-12/31/11 (EDITED/IMPUTED) & 0.049 & 0.012 & 0.004 & 0.015 \\
\hline actlim1.2 & ANY LIMITATION WORK/HOUSEWRK/SCHL-RD 1 & 0.033 & 0.020 & 0.015 & 0.002 \\
\hline coglim1.2 & COGNITIVE LIMITATIONS - RD 1 & 0.026 & 0.003 & 0.001 & 0.012 \\
\hline intrpy $1 x$ & PERSON’S INTEREST INCOME 11 & 0.019 & 0.009 & 0.016 & 0.002 \\
\hline totslfy 1 & TOTAL AMT PAID BY SELF/FAMILY 11 & 0.019 & 0.013 & 0.004 & 0.000 \\
\hline coglim1.1 & COGNITIVE LIMITATIONS - RD 1 & 0.016 & 0.040 & 0.003 & 0.003 \\
\hline
\end{tabular}

PC, principal component.

The numbers after the "." in the variable names indicating the categories. Other variables not shown for limited space. The range of $R$ squared of the input variable is from 0 (no variance of the PCs explained by input variables) to 1 (all of variance of the PCs explained by input variables). 
also not applicable for data with survey design (27, 40). Finally, there remains room for debate on what measures should or could be used to determine life stages. The use of PCs to determine life stages with the social and health data may not be optimal for researchers who need biological or epigenetic measures (41-43).

\section{Future Work}

The abovementioned limitations also suggest more research opportunities that we will explore later. The first of our future research directions will be to demonstrate the use of each PC to other datasets and produce components that can be generalized to future panels of MEPS data and other data sources. The second research opportunity will be to demonstrate the usefulness of the concept of life stages. The priority is to apply this research framework on other longitudinal data sets as the benchmark, such as the Health and Retirement Study (44) that has been widely used in the research community. Third, we will use biomarker database to demonstrate the life stages based on PCs. The fourth opportunity will be the selection of the information sources in specific life stages with different age groups. This aims to partly solve the issues related to questionnaire changes for specific age groups. Fifth, the life stages based on chronological ages may not be optimal, since the biological clock or DNA methylation age may differ to some extent (41). It may be more useful to link the biological ages with the observed life stages.

\section{CONCLUSION}

This study showed that complex datasets like MEPS could be summarized to identify life stages and their major determinants, including the statuses of functionality and cognition, income, and marital status. The identification of stable and transition life stages is important for research that relies on a research population with similar characteristics to draw samples for observation or intervention. There are research opportunities regarding the periods of transitions and the causes of different trajectories.

\section{REFERENCES}

1. Ben-Shlomo Y, Kuh D. A life course approach to chronic disease epidemiology: conceptual models, empirical challenges and interdisciplinary perspectives. Int J Epidemiol (2002) 31(2):285-93. doi:10.1093/ije/31.2.285

2. Kuh D, Ben-Shlomo Y, Lynch J, Hallqvist J, Power C. Life course epidemiology. J Epidemiol Community Health (2003) 57(10):778-83. doi:10.1136/ jech.57.10.778

3. Barker DJ, Osmond C, Forsén TJ, Kajantie E, Eriksson JG. Trajectories of growth among children who have coronary events as adults. $N$ Engl J Med (2005) 353(17):1802-9. doi:10.1056/NEJMoa044160

4. Tirosh A, Shai I, Afek A, Dubnov-Raz G, Ayalon N, Gordon B, et al. Adolescent BMI trajectory and risk of diabetes versus coronary disease. $N$ Engl J Med (2011) 364(14):1315-25. doi:10.1056/NEJMoa1006992

5. Lynn J, Adamson DM. Living well at the end of life. Adapting Health Care to Serious Chronic Illness in Old Age. Santa Monica, CA: RAND Health (2003).

6. Carlson NE, Moore MM, Dame A, Howieson D, Silbert LC, Quinn JF, et al. Trajectories of brain loss in aging and the development of cognitive impairment. Neurology (2008) 70(11):828-33. doi:10.1212/01.wnl.0000280577. 43413.d9

\section{PATIENT CONSENT}

The MEPS data are publicly available, and there is no patient consent form available for download.

\section{AVAILABILITY OF DATA AND MATERIALS}

All data sets can be freely assessed via the Agency for Healthcare Research and Quality website (https://meps.ahrq.gov/data_stats/ download_data_files.jsp).

\section{ETHICS STATEMENT}

This secondary data analysis study was approved by the ethics committee of the Centre hospitalier de l'Université de Montréal (number: 2016-6095).

\section{AUTHOR CONTRIBUTIONS}

Y-SC conceptualized the research project, restructured the data, conducted the statistical analyses, and drafted the manuscripts. $\mathrm{H}$-TW provided suggestions from different aspects and revised the manuscript. C-JW reviewed the manuscript and provided constructive comments.

\section{ACKNOWLEDGMENTS}

Y-SC was financed by the Fonds de recherche du Québec - Santé (FRQS) fellowship. The granting agencies had no role in this study. The authors would like to thank Edward Ng for his useful comments.

\section{SUPPLEMENTARY MATERIAL}

The Supplementary Material for this article can be found online at http://journal.frontiersin.org/article/10.3389/fpubh.2017.00247/ full\#supplementary-material.

7. Weiss ST. Lung function and airway diseases. Nat Genet (2010) 42(1):14-6. doi:10.1038/ng0110-14

8. Gill TM, Gahbauer EA, Han L, Allore HG. Trajectories of disability in the last year of life. N Engl J Med (2010) 362(13):1173-80. doi:10.1056/ NEJMoa0909087

9. Murray SA, Kendall M, Boyd K, Sheikh A. Illness trajectories and palliative care. BMJ (2005) 330(7498):1007-11. doi:10.1136/bmj.330.7492.611

10. Covinsky KE, Eng C, Lui LY, Sands LP, Yaffe K. The last 2 years of life: functional trajectories of frail older people. J Am Geriatr Soc (2003) 51(4):492-8. doi:10.1046/j.1532-5415.2003.51157.x

11. Rosset E. Old age and the frequency of surviving to this age. Aging Process of Population. Amsterdam, Netherlands: Elsevier Science (2013).

12. Cohen SB, Cohen JW. The capacity of the Medical Expenditure Panel Survey to inform the Affordable Care Act. Inquiry (2013) 50(2):124-34. doi:10.1177/0046958013513678

13. Bernard D, Selden T. Employer offers, private coverage, and the tax subsidy for health insurance: 1987 and 1996. Int J Health Care Finance Econ (2002) 2(4):297-318. doi:10.1023/A:1022360202017

14. Selden TM, Bernard DM. Tax incidence and net benefits in the market for employment-related health insurance: sensitivity of estimates to the incidence 
of employer costs. Int J Health Care Finance Econ (2004) 4(2):167-92. doi:10.1023/B:IHFE.0000032422.90886.86

15. Guner N, Kulikova Y, Llull J. Does marriage make you healthier? (2014). CEPR Discussion Paper No. DP10245. Available from: https://ssrn.com/ abstract $=2526358$

16. Cohen JW, Monheit AC, Beauregard KM, Cohen SB, Lefkowitz DC, Potter DE, et al. The Medical Expenditure Panel survey: a national health information resource. Inquiry (1996) 33(4):373-89.

17. Agency for Healthcare Research and Quality. MEPS-HC Sample Design and Collection Process (2015). Available from: http://www.meps.ahrq.gov/ survey_comp/hc_data_collection.jsp

18. Buuren S, Groothuis-Oudshoorn K. mice: multivariate imputation by chained equations in R. J Stat Software (2011) 45(3):1-67. doi:10.18637/jss. v045.i03

19. Duffy ME, Jacobsen BS. Univariate descriptive statistics. In: Munro BH, editor. Statistical Methods for Health Care Research. Philadelphia, PA: Lippincott Williams \& Wilkins (2005). p. 33-72.

20. Hall MA, Smith LA, editors. Feature subset selection: a correlation based filter approach. 1997 International Conference on Neural Information Processing and Intelligent Information Systems. Berlin: Springer (1997).

21. Saeys Y, Inza I, Larranaga P. A review of feature selection techniques in bioinformatics. Bioinformatics (2007) 23(19):2507-17. doi:10.1093/bioinformatics/ btm344

22. Agency for Healthcare Research and Quality, editor. MEPS HC-147 2011 Full Year Consolidated Data File. Rockville, MD: Agency for Healthcare Research and Quality (2013). p. C-29.

23. Kuhn M. Building predictive models in R using the caret package. J Stat Softw (2008) 28(5):1-26. doi:10.18637/jss.v028.i05

24. Everitt BS, Hothorn T. Principal component analysis. A Handbook of Statistical Analyses Using R. London: Chapman and Hall/CRC (2006). p. 215-26.

25. Lumley T. Analysis of complex survey samples. J Stat Software (2004) 9(8):19. doi:10.18637/jss.v009.i08

26. He R, Hu B, Yuan X, Zheng W-S. Principal component analysis based on non-parametric maximum entropy. Neurocomput (2010) 73(10-12):1840-52. doi:10.1016/j.neucom.2009.12.032

27. Jolliffe IT. Principal Component Analysis. New York: Springer (2013).

28. Oja H. Multivariate Nonparametric Methods with R: An approach Based on Spatial Signs and Ranks. New York: Springer (2010).

29. Hastie T, Tibshirani R, Friedman JH. The Elements of Statistical Learning: Data Mining, Inference, and Prediction. New York, NY: Springer (2001).

30. Lumley T. Basic tools. Complex Surveys. Hoboken, NJ: John Wiley \& Sons, Inc (2010). p. 1-15.

31. Krzywinski M, Altman N. Points of significance: comparing samples - part II. Nat Meth (2014) 11(4):355-6. doi:10.1038/nmeth.2858
32. Grömping U. Relative importance for linear regression in R: the package relaimpo. J Stat Software (2006) 17(1):1-27. doi:10.18637/jss.v017.i01

33. Greenland S, Rothman KJ. Introduction to categorical statistics. In: Rothman KJ, Greenland S, Lash TL, editors. Modern Epidemiology. Philadelphia, PA: Wolters Kluwer Health/Lippincott Williams \& Wilkins (2008). p. 239-58.

34. Szklo M, Nieto J. Epidemiology. Burlington, MA: Jones \& Bartlett Learning (2012).

35. Patten S. Epidemiology for Canadian Students: Principles, Methods and Critical Appraisal. Edmonton, Alberta: Brush Education (2015).

36. Ringner M. What is principal component analysis? Nat Biotech (2008) 26(3):303-4. doi:10.1038/nbt0308-303

37. Saczynski JS, Marcantonio ER, Quach L, Fong TG, Gross A, Inouye SK, et al. Cognitive trajectories after postoperative delirium. N Engl J Med (2012) 367(1):30-9. doi:10.1056/NEJMoa1112923

38. Hsu HC, Jones BL. Multiple trajectories of successful aging of older and younger cohorts. Gerontologist (2012) 52(6):843-56. doi:10.1093/geront/ gns005

39. Oberlander J. The future of Obamacare. N Engl J Med (2012) 367(23):2165-7. doi:10.1056/NEJMp1213674

40. Scholz M, Kaplan F, Guy CL, Kopka J, Selbig J. Non-linear PCA: a missing data approach. Bioinformatics (2005) 21(20):3887-95. doi:10.1093/bioinformatics/ bti634

41. Horvath S. DNA methylation age of human tissues and cell types. Genome Biol (2013) 14(10):R115. doi:10.1186/gb-2013-14-10-r115

42. Vallejo AN. Immune aging and challenges for immune protection of the graying population. Aging Dis (2011) 2(5):339-45.

43. Quanjer PH, Stanojevic S, Cole TJ, Baur X, Hall GL, Culver BH, et al. Multi-ethnic reference values for spirometry for the 3-95-yr age range: the global lung function 2012 equations. Eur Respir J (2012) 40(6):1324-43. doi:10.1183/09031936.00080312

44. Juster FT, Suzman R. An overview of the health and retirement study. J Hum Resour (1995) 30:S7-56. doi:10.2307/146277

Conflict of Interest Statement: The authors declare that the research was conducted in the absence of any commercial or financial relationships that could be construed as a potential conflict of interest.

Copyright $\odot 2017$ CHAO, Wu and Wu. This is an open-access article distributed under the terms of the Creative Commons Attribution License (CC BY). The use, distribution or reproduction in other forums is permitted, provided the original author(s) or licensor are credited and that the original publication in this journal is cited, in accordance with accepted academic practice. No use, distribution or reproduction is permitted which does not comply with these terms. 